\title{
Mycology of otomycosis and the role of antifungal drops versus antifungal cream in the treatment of otomycosis: an observational study
}

\author{
V. Sneha Lekha, V. Neelima Priyadarshini, Siva Subba Rao Pakanati*, K. Dilip Kumar
}

Department of ENT, Mamata Medical College, Khammam, Telangana, India

Received: 16 June 2021

Accepted: 02 July 2021

\section{*Correspondence:}

Dr. Siva Subba Rao Pakanati,

E-mail: pakanati.sivasubbarao@gmail.com

Copyright: ( $)$ the author(s), publisher and licensee Medip Academy. This is an open-access article distributed under the terms of the Creative Commons Attribution Non-Commercial License, which permits unrestricted non-commercial use, distribution, and reproduction in any medium, provided the original work is properly cited.

\section{ABSTRACT}

Background: Aim of the study was to determine most common mode of presentation, spectrum of fungi involved in otomycosis and to compare the treatment efficacy of $1 \%$ clotrimazole drops with $1 \%$ clotrimazole cream in management of otomycosis.

Methods: A prospective observational study was conducted over a study period of 18 months, in which a total of 60 patients who are clinically diagnosed with otomycosis were included. All the specimens collected from patients were subjected to standard microbiological procedures for identification of fungi involved in otomycosis. Then patients were randomly allotted into 2 groups for treatment with $1 \%$ clotrimazole drops or with cream. Improvement in symptoms of pain, pruritis, blocked sensation, and discharge on one-and two-weeks follow-up was recorded. External auditory canal was evaluated for improvement in otomycotic debris. All patients were asked the opinion about preferred modality of treatment.

Results: In our study, Aspergillus niger 27(45\%) was the predominant species isolated. When compared to the symptoms on day 01 at day 07 , significant difference was noted for the improvement of the symptoms and also for the otomycotic debris in both the groups. The group with cream had significantly more blocked sensation. On second week follow up, significant improvement was noted for all the symptoms and otomycotic debris. Forty five out of sixty patients preferred using cream.

Conclusions: In our study, Aspergillus species was found to be the commonest fungi involved in otomycosis. $1 \%$ topical clotrimazole drops and cream were equally effective in management of otomycosis.

Keywords: Otomycosis, Aspergillus, $1 \%$ clotrimazole, Drops, Cream

\section{INTRODUCTION}

Otomycosis, also known as fungal otitis externa is one of the most common conditions encountered in a general ENT practice. Wide spread use of steroid and antibiotic drops or prior otologic procedures have led to increase in prevalence of this condition. ${ }^{1,2}$ Prevalence of this condition is more in tropical and subtropical humid climates. A high prevalence rate of $9 \%$ has been mentioned for otomycosis amongst patients presenting with otitis externa. ${ }^{3}$ The common organism that causes otomycosis are Aspergillus fumigatus, Aspergillus niger, Candida albicans of which Aspergillus niger is found to be pre-dominant. ${ }^{4,5}$ Though this condition is not fatal it does present a challenge for otolaryngologists for it often needs long-term treatment and follow-up. It also tends to recur quite often.

Predisposing factors such as a failure in the ear's defence mechanisms (changes in the coating epithelium, changes in $\mathrm{pH}$, quantitative and qualitative changes in ear wax), bacterial infection, instillation of oil, hearing aid or a hearing prosthesis, self-inflicted trauma, swimming, broad spectrum antibiotic agents, steroids and cytostatic medication, neoplasia and immune disorders, all of which 
can render the host susceptible to the development of otomycosis. $^{4,5}$

Treatment recommendations go from germ termination or controlling predisposing factors, to local debridement (micro-aspiration) and/or the use of antimicrobial agents (topical/systemic). ${ }^{8}$ Studies show clotrimazole as one of the most effective agents for management of otomycosis, with reported efficacy rate of $95 \%$ to $100 \%$. It is available as powder, lotion, and solution and is considered free of ototoxic effects. Commonly topical Clotrimazole drops are used 2 to 3 times a day for 7 to 10 days or till cure. Putting drops so frequently for long is definitely cumbersome especially for office class patients. In this study, we aimed at determining the most common mode of presentation, the spectrum of fungi, and to compare the efficacy of $1 \%$ clotrimazole drops and $1 \%$ clotrimazole cream.

\section{METHODS}

It is an observational study conducted over a period of 18 months from October 2019 to March 2021 in the department of ENT, Mamata medical college, Khammam where patients were prospectively recruited who are suspects of otomycosis with a sample size of 60 . Inclusion criteria consisted of all consenting patients with otomycosis. Patients with tympanostomy tube in situ, chronic otitis media, mastoidectomy cavity, uncontrolled diabetics, and those using hearing aids were excluded from this study. Diagnosis of otomycosis was based on clinical features and otoscopic findings of hyphae, fruiting bodies, thick whitish cheesy material. Patients were told to rate the symptoms as per visual analogue scale. The symptoms were otalgia, pruritis, blocked sensation, pruritis, otorrhea.

All the specimens for mycological study were collected using two sterile cotton tipped swabs or sterile scalpel blade. First swab/scrapped material was applied on glass slide and treated with a drop of $10 \% \mathrm{KOH}$. Second swab/scrapped material was inoculated on two Sabouraud's dextrose agar with chloramphenicol. One of the agar slants was incubated at room temperature $\left(25^{\circ} \mathrm{C}\right)$ and the other was incubated at $37^{\circ} \mathrm{C}$ for 2 to 3 weeks. Cultures were examined for growth on alternate days. Fungi were identified by standard procedures.

By simple random sampling techniques, patients were allotted into two groups. Group A consisted of $1 \%$ clotrimazole drops and group B consisted of $1 \%$ clotrimazole cream. Group A patients were instructed to instill $1 \%$ clotrimazole drops three drops three times a day and to review in OPD after a week. For group B, under endoscopic guidance, $1 \%$ clotrimazole cream is instilled into external auditory canal (EAC) using $2 \mathrm{ml}$ syringe and asked to review after a week.

During follow up the symptoms were evaluated again and EAC was examined. Patient was considered treated when there was no evidence of residual fungal debris. If during the first visit patient had evidence of otomycosis, the treatment was repeated and patient reviewed again after a week. After cure all the patients were asked a standard question. "If the results are same, will they prefer one time instillation of cream or topical drops which needs to be instilled daily three times". The answer was noted.

\section{RESULTS}

Out of 60 specimens collected from patients of otomycosis, 29 patients were males and 31 were females. Predominant otomycosis was found in the age group of 21-30 years followed by 11-20 years, (Table 1 ).

Table 1: Age and sex distribution.

\begin{tabular}{|llll|}
\hline Age $($ years) & Male sex & Female sex & Total $(\%)$ \\
\hline $\mathbf{1 1 0}$ & 2 & 1 & $3(5)$ \\
\hline $\mathbf{1 1 - 2 0}$ & 6 & 7 & $13(21.6)$ \\
\hline $\mathbf{2 1 - 3 0}$ & 8 & 9 & $17(28.3)$ \\
\hline $\mathbf{3 1 - 4 0}$ & 4 & 5 & $9(15)$ \\
\hline $\mathbf{4 1 - 5 0}$ & 4 & 5 & $9(15)$ \\
\hline $\mathbf{5 1 - 6 0}$ & 3 & 2 & $5(8.3)$ \\
\hline$>\mathbf{6 0}$ & 2 & 2 & $4(6.6)$ \\
\hline Total & $29(48.33)$ & $31(51.6)$ & $60(100)$ \\
\hline
\end{tabular}

Out of the 60 specimens collected, all the specimens yielded single organism. Aspergillus niger 27 (45\%) was the predominant species isolated. Second most common species isolated was Aspergillus flavus 16 (26.6\%), (Figure 1).

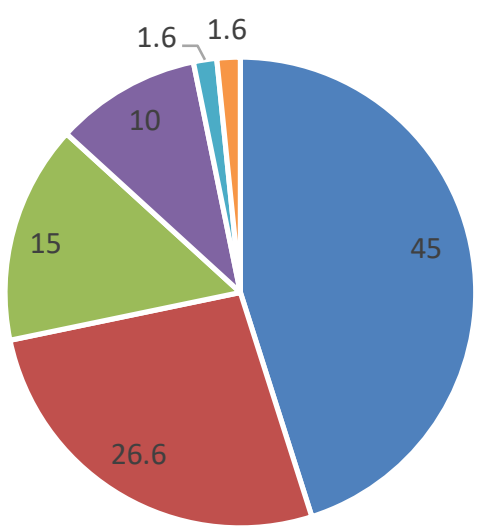

$$
\begin{array}{ll}
\text { - Aspergillus niger } & \text { - Aspergillus flavus } \\
\text { - Aspergillus fumigatus } & \text { - Candida } \\
\text { - Mucor } & \text { - Pencillium }
\end{array}
$$

Figure 1: Results of fungal culture.

Of the total 60 patients, patients were divided into two groups, 30 patients in each group, with their symptoms noted (Table 2). 
Table 2: Symptoms in both the groups at the start of the treatment.

\begin{tabular}{|lll|}
\hline Symptoms at the start of the & Group & Group \\
treatment & A & B \\
\hline Pain & 29 & 28 \\
\hline Blocked sensation & 28 & 26 \\
\hline Pruritis & 26 & 27 \\
\hline Discharge & 14 & 12 \\
\hline Otomycotic debri & 28 & 28 \\
\hline
\end{tabular}

In both the groups, all the patients were evaluated after seven days and the same symptoms were noted. External auditory canal was checked with endoscope and the findings were recorded. The results at the end of first week is as per Table 3.

Table 3: Number of patients in each group of persistence of symptoms after a week.

\begin{tabular}{|lll|}
\hline $\begin{array}{l}\text { Persistence of symptoms after } \\
\text { first week }\end{array}$ & Group & Group \\
\hline Persistence of pain & 10 & 12 \\
\hline Pruritis & 7 & 6 \\
\hline Discharge & 2 & 3 \\
\hline Persistence of otomycotic debri & 10 & 12 \\
\hline Persistence of ear block & 13 & 22 \\
\hline
\end{tabular}

After a week review, there was a symptomatic improvement between both the groups except for symptom of ear blockage. The group with cream had significantly more sensation of ear blockage compared to the drops group. The result of change in symptoms after 2 weeks is as per Figure 2.

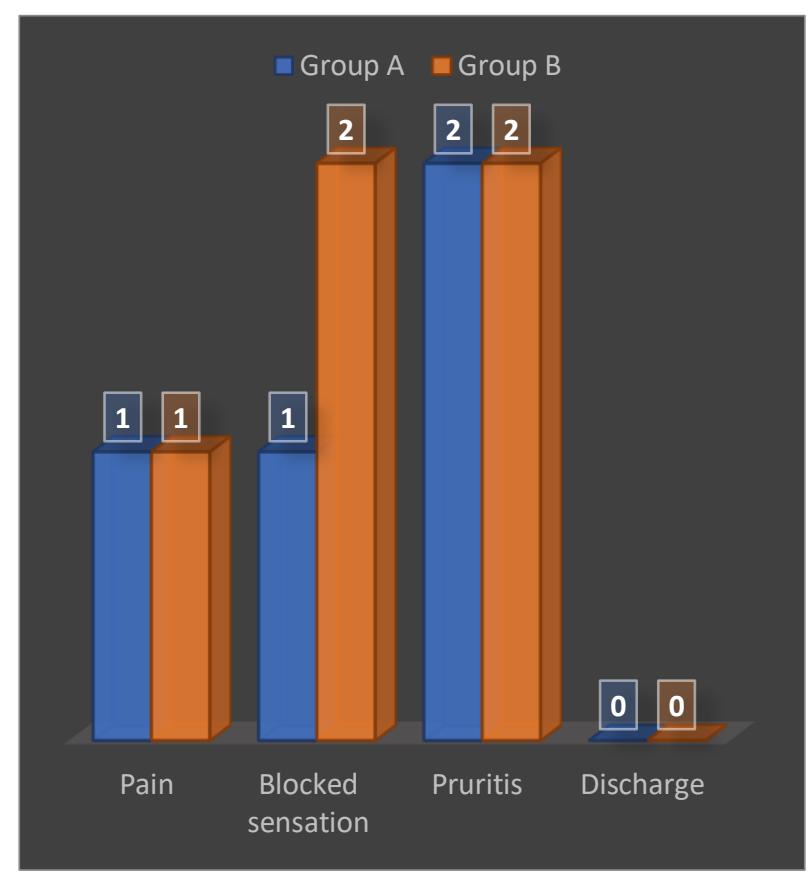

Figure 2: Symptomatic change after 2-week follow-up with visual analogue scale on $\mathrm{Y}$-axis.
On second week follow-up, significant improvement was noticed for all the symptoms when compared to the symptoms on day-1, and there was no significant difference between the two groups in terms of symptoms and otomycotic debris. For the response to the question asked to all the patients at the end regarding choosing the preferred modality of treatment (drops vs. cream) given that the efficacy was same, 45 out of 60 patients preferred using cream considering the convenience of treatment modality.

\section{DISCUSSION}

Otomycosis is a common condition encountered in ENT out patient department which consists of fungal infection of the external auditory canal wall. The patient mainly presents with otalgia, pruritis, block sensation, and otoscopy shows presence of otoscopy finding of matted hyphae, spores, or curdy precipitate in the external auditory canal. Study by Pradhan suggested pruritis as the main symptom of otomycosis. ${ }^{9}$ Most common symptoms of otomycosis are pruritis, hearing loss, ear discharge and ear pain. This is in agreement with the other studies. ${ }^{10,11}$

In our study, Aspergillus niger was the most commonly isolated organism. This is in accordance with the other studies. ${ }^{12,13}$ Use of appropriate antifungal agent along with mechanical debridement remains the mainstay of treatment. Amongst antifungals topical clotrimazole remains widely used agent. ${ }^{14} 1 \%$ clotrimazole cream has been used for treatment of this condition with good efficacy. ${ }^{15}$ In present study too patients gave good response with use of cream. Patients using $1 \%$ clotrimazole drops have to in still drops in affected ear three to four times a day. This can become very cumbersome for office going person. Besides, direct instillation of antifungal solution is also associated with burning sensation especially in cases of perforated drum. ${ }^{16}$

There are not many studies comparing the use of $1 \%$ clotrimazole drops with that of $1 \%$ cream in treatment of otomycosis. Study by Halawa et al used clotrimazole ointment for otomycosis and compared use of wick with regular application and found that self-application and wick application both have same efficacy for relief from otomycosis. ${ }^{16}$ Blocked sensation was more in patients in whom topical cream was used which is a known fact as reported by Hurst. ${ }^{17}$ It takes around 2 to 3 weeks to achieve cure from disease. Thus, to reduce chance of recurrence and to improve patient well-being as well as considering the ease of installation, the present study compared cream vs. drops.

\section{CONCLUSION}

From this prospective observational study, it can be concluded that the most common fungal agent for otomycosis was Aspergillus niger and the use of $1 \%$ topical clotrimazole drops and $1 \%$ clotrimazole cream 
were equally effective in management of otomycosis. Cream leads to more block sensation during the first seven days when compared to drops.

Funding: No funding sources

Conflict of interest: None declared

Ethical approval: The study was approved by the Institutional Ethics Committee

\section{REFERENCES}

1. Chander J, Maini S, Subrahmanyan S, Handa A. Otomycosis-a clinic-mycological study and efficacy of mercurochrome in its treatment. Mycopathologia. 1996;135(1):9-12.

2. Ho T, Vrabec JT, Yoo D, Coker NJ. Otomycosis: clinical features and treatment implications. Otolaryngol Head Neck Surg. 2006;135(5):787-91.

3. Mugliston T, O’Donoghue G. Otomycosis: a continuing problem. J Laryngol Otol. 1985;99(4):327-33.

4. Kaur R, Mittal N, Kakkar M, Aggarwal AK, Mathur MD. Otomycosis: a clinicomycologic study. Ear Nose Throat J. 2000;79(8):606-9.

5. Hoshino T, Matsumoto M. Otomycosis: Subdermal growth in calcified mass. Eur Arch Otorhinolaryngol. 2006;263(9):875-8.

6. Fasunla J, Ibekwe T, Onakoya P. Otomycosis in western Nigeria. Mycoses. 2007;51:67-70.

7. Jackman A. Case report topical antibiotic induced otomycosis. Int $\mathbf{J}$ Pediatr Otorhinolaryngol. 2005;69:957-60.

8. Hurst WB. Outcome of 22 cases of perforated tympanic membrane caused by otomycosis. J Laryngol Otol. 2001;115:879-80.

9. Pradhan B, Tuladhar NR, Amatya RM. Prevalence of otomycosis in outpatient department of otolaryngology in Tribhuvan University Teaching
Hospital, Kathmandu, Nepal. Ann Otol Rhinol Laryngol. 2003;112(4):384-7.

10. Pradhan B, Tuladhar NR, Amatya RM. Prevalence of otomycosis in outpatient dept of otologyngology in Tribhuvan University teaching hospital, Kathmandu, Nepal. Ann Otol Rhinol Laryngol. 2003;112:384-7.

11. Murat Ozcan K, Ozcan M, Karaarslan A, Karaarslan F. Otomycosis in Turkey: predisposing factors, aetiology and therapy. The $\mathrm{J}$ Laryngol Otol. 2003; 117:39-42.

12. Ghiacei S. Survey of Otomycosis in north-western area of Iran. Med J Mashhad Uni Med Sci. 2001;43:85-7.

13. Sephidgar A, Kyakajouri K, Meyrzaei M, Sharifi F. Fungal infection of external ear in otomycosis. J Babol Med Sci. 2001;13:25-9.

14. Anwar K, Gohar MS. Otomycosis; clinical features, predisposing factors and treatment implications. Pak J Med Sci. 2014;30(3):564-7.

15. Ologe FE, Nwabuisi C. Treatment outcome of otomycosis in Ilorin, Nigeria. West Afr $\mathrm{J}$ Med. 2002;21(1):34-6.

16. Abou-halawa AS, Khan MA, AlRobaee AA, Alzolibani AA, AlShobaili HA. Otomycosis with Perforated Tympanic Membrane: Self-medication with Topical Antifungal Solution versus Medicated Ear Wick. Int J Health Sci (Qassim). 2012;6(1):73-7.

17. Hurst WB. Outcome of 22 cases of perforated tympanic membrane caused by otomycosis. J Laryngol Otol. 2001;115(11):879-80.

Cite this article as: Lekha VS, Priyadarshini VN, Pakanati SSR, Kumar KD. Mycology of otomycosis and the role of antifungal drops versus antifungal cream in the treatment of otomycosis: an observational study. Int J Otorhinolaryngol Head Neck Surg 2021;7:1343-6. 